

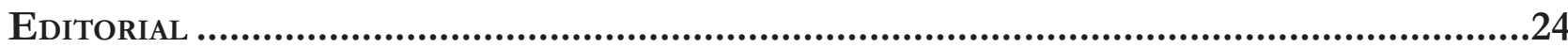

O Direito na fronteira da razão: Psicologia, neurociência e economia comportamental................... 24 Patrícia Perrone Campos Mello e Sergio Nojiri

I. NeURodireito: COGNIÇão, EMOÇÃo, JUÍZOS MORAIS E CIÊNCIA ..........................................26

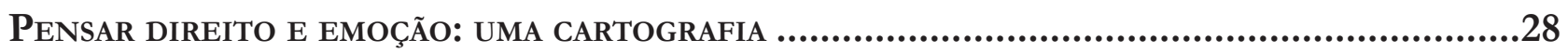

Nevita Maria Pessoa de Aquino Franca Luna

Neurodireito: o início, o fim E O MEIO

Carlos Marden e Leonardo Martins Wykrota

ENSAIO JURÍDICO SOBRE A RACIONALIDADE HUMANA: MAIORES, CAPAZES E IRRACIONAIS

André Perin Schmidt Neto e Eugênio Facchini Neto

DIVERGÊNCIAS DE PRINCÍPIO: ARGUMENTOS JURÍDICOS E MORAIS EM UM CENÁRIO DE DESACORDOS SOCIAIS

André Matos de Almeida Oliveira, Pâmela de Rezende Côrtes e Leonardo Martins Wykrota

CONSILIÊNCIA E A POSSIBILIDADE DO NEURODIREITO: DA DESCONFIANÇA À RECONCILIAÇÃO DISCIPLINAR.....

Thaís de Bessa Gontijo de Oliveira e Renato César Cardoso

MODELOS DE MORALIDADE

Molly J. Crockett

A INFELIZ BUSCA POR FELICIDADE No DiREITo

Úrsula Simões da Costa Cunha Vasconcellost, Noel Struchiner e Ivar Hannikainen

Além da liberdade: PersPeCtivas Em Nietzsche.

Lucas Costa de Oliveira

A mediaÇão de CONFlitos SOb a PERSPECTIVA do DESENVOLVIMENTO HUMANO: AS CONTRIBUIÇÕES DA PSICOLOGIA POSITIVA

Simone de Biazzi Ávila Batista da Silveira e Deise Brião Ferraz

Neuroimagiologia e aValiação de ResPonsabilidade

Nicole A. Vincent 
ANÁLISE CRÍTICA DA ORIENTAÇÃO DE CIDADÃOS COMO MÉTODO PARA OTIMIZAR DECISÕES PÚBLICAS POR MEIO DA TÉCNICA NUDGE.

Luciana Cristina Souza, Karen Tobias França Ramos e Sônia Carolina Romão Viana Perdigão

Políticas públicas e o deVer de monitoramento: “LEVANdo os Direitos A SÉrio". .252 Ana Paula de Barcellos

Nudges E POLÍticas PÚblicas: uM MECANISMO DE COMBATE AO TRABALHO EM CONDIÇÃo ANÁLOGA À DE ESCRAVO .267

Amanda Carolina Souza Silva, Débhora Renata Nunes Rodrigues e Saul Duarte Tibaldi

REDUZINDO A TRIBUTAÇÃO COGNITIVA: LIÇÕES COMPORTAMENTAIS PARA A DIMINUIÇÃO DOS EFEITOS PSICOLÓGICOS ADVERSOS DA POBREZA.............................................................288 Leandro Novais e Silva, Luiz Felipe Drummond Teixeira, Gabriel Salgueiro Soares e Otávio Augusto Andrade Santos

Políticas PÚBLICAS EM SUICÍDIO: DO PATERNALISMO CLÁSSICO AO PATERNALISMO LIBERTÁRIO E NUDGING

Davi de Paiva Costa Tangerino, Gabriel Cabral e Henrique Olive

Nudges COMO POLÍticA PÚbliCA PARA AUMENTAR O ESCASSO NÚMERO DE DOADORES DE ÓRGÃos PARA TRANSPLANTE

Roberta Marina Cioatto e Adriana de Alencar Gomes Pinheiro

Os PROGRAMAS DE INTEGRIDADE PARA CONTRATAÇÃO COM A ADMINISTRAÇÃO PÚBLICA ESTADUAL: NUDGE OU OBRIGAÇÃo LEGAL? UM OLHAR SOBRE AS DUAS PERSPECTIVAS .386

Cíntia Muniz Rebouças de Alencar Araripe e Raquel Cavalcanti Ramos Machado

Paternalismo libertário e Proteção JURídica do AMbiente: POR QUe PROTEger o AMBIENTE TAMBÉM DEVE SER PROTEGER AS LIBERDADES?

Mariana Carvalho Victor Coelho e Patryck de Araujo Ayala

Políticas PÚblicas baseadas EM EVIdÊNCIAS COMPORTAMENTAIS: REFLEXões A PARTIR do Projeto de Lei 488/2017 do Senado

Pâmela de Rezende Côrtes, André Matos de Almeida Oliveira e Fabiano Teodoro de Rezende Lara

III. ECONOMIA COMPORTAMENTAL: VIESES COGNITIVOS E POLÍTICAS PÚBLICAS .455

ECONOMIA COMPORTAMENTAL E DIREITO: A RACIONALIDADE EM MUDANÇA Marcia Carla Pereira Ribeiro e Victor Hugo Domingues

VIESES COGNITIVOS E DESENHO DE POLÍTICAS PÚBLICAS 
A neurociênCia da moralidade na tomada de DeCisões Jurídicas Complexas e No DESENHO DE POLÍTICAS PÚBLICAS

Erik Navarro Wolkart

Desvio de CARÁter ou SIMPLESMENTE HUMANO? ECONOMIA COMPORTAMENTAL APLICADA AO COMPORTAMENTO DESONESTO

Diana Orghian, Gabriel Cabral, André Pinto e Alessandra Fontana

Políticas Públicas e a ConcretizaÇão de direitos sociais: TOMAdA DE DECisão, ARQUITETURA DE ESCOLHAS E EFETIVIDADE

Ana Elizabeth Neirão Reymão e Ricardo dos Santos Caçapietra

BEHAVIORAL ECONOMICS E DIREITO DO CONSUMIDOR: NOVAS PERSPECTIVAS PARA O ENFRENTAMENTO DO SUPERENDIVIDAMENTO .568

Samir Alves Daura

A EDUCAÇÃo FORMAL PARA O CONSUMO É GARANTIA PARA UMA PRESENÇA REFLETIDA DO CONSUMIDOR NO MERCADO? UMA ANÁLISE COM BASE NA BEHAVIORAL LAW AND ECONOMICS (ECONOMIA COMPORTAMENTAL) 600

Marcia Carla Pereira Ribeiro e Edson Mitsuo Tiujo

LIBET, DETERMINISMO E CONSUMO: AS INFLUÊNCIAS DO MARKETING E A RELEVÂNCIA DA DELIBERAÇÃo CONSCIENTE NA SUPERAÇÃo CONDICIONAL DE HÁBITOS DE CONSUMO PERIGOSOS616 Émilien Vilas Boas Reis e Leonardo Cordeiro de Gusmão

CiÊNCIA DO DIREITO TRIBUTÁRIO, ECONOMIA COMPORTAMENTAL E EXTRAFISCALIDADE. .640 Hugo de Brito Machado Segundo

IV. CoMportamento JUdiCiAL: INFLUÊNCIA DE FATORES EXTRAJURÍDicos .660

FATORES METAPROCESSUAIS E SUAS INFLUÊNCIAS PARA A FORMAÇÃo DA DECISÃo JUDICIAL .662 Rogério Roberto Gonçalves de Abreu, Lúcio Grassi de Gouveia e Virgínia Colares

“A VIDA COMO ELA É": COMPORTAMENTO ESTRATÉGICO NAS CORTES Patrícia Perrone Campos Mello

A COMPOSIÇÃo do ÓRGão COLEGIAdo E SEUS EFEITOS NA TOMADA DE DECISÃo .720 André Garcia Leão Reis Valadares

Das 11 ilhas ao centro do arquipélago: os superpoderes do Presidente do STF DURANTE O RECESSO JUDICIAL E FÉRIAS .741 José Mário Wanderley Gomes Neto e Flávia Danielle Santiago Lima 
RAZÃo, EMOÇÃo E DELIBERAÇÃO: AS ADEQUAÇÕES REgIMENTAIS do SUPERIOR TribUNAL DE JUSTIÇA PARA A FORMAÇÃo DE PRECEDENTES EFICAZES

Peter Panutto e Lana Olivi Chaim

Heurística de ancoragem e fiXaÇÃo de danos morais em JUizados especiais Cíveis no Rio DE JANEIRO: UMA NOVA ANÁLISE 778

Fernando Leal e Leandro Molhano Ribeiro

LA PROTECCIÓN DE LOS DERECHOS POLÍTICOS FRENTE A LAS FUNCIONES DISCIPLINARIAS DE LAS AUTORIDADES ADMINISTRATIVAS: SUBSIDIARIEDAD Y DEFERENCIA EN EL SISTEMA INTERAMERICANO DE DERECHOS HUMANOS Jorge Ernesto Roa Roa

V. A influênCia do gÊNERo no PROCESSO DECisório JUdiCial

Como os Juízes decidem os Casos de estupro? ANALISANDo SENTENÇAS SOb A PERSPECTIVA DE VIESES E ESTEREÓTIPOS DE GÊNERO 826 Gabriela Perissinotto de Almeida e Sérgio Nojiri

GÊNERO E COMPORTAMENTO JUDICIAL NO SUPREMO TRIBUNAL FEDERAL: OS MINISTROS CONFIAM MENOS EM RELATORAS MULHERES?

Juliana Cesario Alvim Gomes, Rafaela Nogueira e Diego Werneck Arguelhes

Hércules, Hermes e a Pequena Sereia: uma reflexão sobre estereótipos de gênero, SUBPRESENTAÇÃo DAS MULHERES NOS TRIBUNAIS E (I)LEGITIMIDADE DEMOCRÁTICA DO PODER JUDICIÁRIO. .878 Jane Reis Gonçalves Pereira e Renan Medeiros de Oliveira

Prisão Cautelar de gestantes: análise do Fundamento filosófico da decisão do Habeas CoRpus N. 143.641 912

Artur César Souza e Giovania Tatibana de Souza

VI. Neurodireito APlicado ao direito E Ao Processo PENAL....................................926

CÉREbros QUe PUNEM: UMA REVISÃo CRÍTICA DA NEURoCIÊNCIA DA PUNIÇÃo .....................928 Ricardo de Lins e Horta

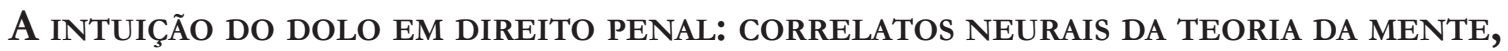
RACIOCÍNIO INDUTIVO E A GARANTIA DA CONVICÇÃO JUSTIFICADA. .946 Thiago Dias de Matos Diniz e Renato César Cardoso

As COMUNIDADES EPISTÊMICAS PENAIS E A PRODUÇÃo LEGISLATIVA EM MATÉRIA CRIMINAL..... 961 Stéphane Enguéléguélé 
DELINQUÊNCIA JUVENIL: RELAÇÕES ENTRE DESENVOLVIMENTO, FUNÇÕES EXECUTIVAS E COMPORTAMENTO SOCIAL NA ADOLESCÊNCIA .

André Vilela Komatsu, Rafaelle CS Costa e Marina Rezende Bazon

Límites TEMPORALES A LAS PENAS PRIVATIVAS DE LIBERTAD ATENDIENDO AL DESARROLLO PSICOSOCIAL.

Silvio Cuneo Nash

NEURolaw E AS PERSPECTIVAS PARA UMA ANÁLISE OBJETIVA DO COMPORTAMENTO SUGESTIONADO: REPERCUSSÃO DAS FALSAS MEMÓRIAS NA ESFERA PENAL

Mariana Dionísio de Andrade, Marina Andrade Cartaxo e Rafael Gonçalves Mota

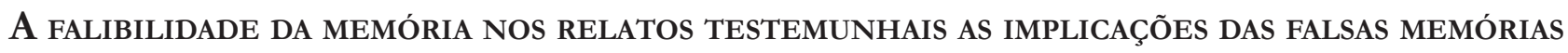
NO CONTEXTO DOS CRIMES CONTRA A DIGNIDADE SEXUAL

Caroline Navas Viana

A (IR)REPETIBILIDADE dA PROVA PENAL DEPENDENTE DA MEMÓRIA: UMA DisCUSSÃo COM BASE NA PSICOLOGIA DO TESTEMUNHO. 1058

William Weber Cecconello, Gustavo Noronha de Avila e Lilian Milnitsky Stein 


\section{Análise crítica da orientação de cidadãos como método para otimizar decisões públicas por meio da técnica nudge*}

\section{Critical analysis of citizens 'orientation as a method of optimize public decisions through nudge technique}

\author{
Luciana Cristina Souza** \\ Karen Tobias França Ramos*** \\ Sônia Carolina Romão Viana Perdigão****
}

* Recebido em 31/05/2018

Aprovado em 19/08/2018

** Doutorado em Direito pela PUC Minas. Professora de Direito Constitucional do Mestrado em Relações Sociais e Econômicas da Faculdade de Direito Milton Campos; Professora da disciplina Estado Democrático e Políticas Públicas da FaPP/UEMG; Coordenadora do Núcleo de Estudos sobre Gestão de Políticas Públicas (NEGESP), registrado no DGP-CNPq; Pesquisadora FAPEMIG. E-mail: dralucianacsouza@gmail.com

*** Mestranda em Direito nas Relações Econômicas e Sociais pela Faculdade Milton Campos. Membro do grupo de pesquisa Núcleo de Estudos sobre Gestão de Políticas Públicas - NEGESP da Faculdade de Direito Milton Campos. Advogada. E-mail: karentfr@ gmail.com

**** Mestranda em Direito nas Relações Econômicas e Sociais pela Faculdade Milton Campos. Membro do grupo de pesquisa Núcleo de Estudos sobre Gestão de Políticas Públicas - NEGESP da Faculdade de Direito Milton Campos. Advogada. E-mail: soninha. carolina@hotmail.com

\section{Resumo}

Este artigo objetiva refletir criticamente sobre a viabilidade de aplicação da técnica de nudge em processos decisórios públicos envolvendo Estado e cidadãos com base na perspectiva do soft paternalism como proposto por Thaler e Sunstein. A formulação de agenda e outras etapas das políticas públicas, conforme o modelo democrático assumido pelo Estado brasileiro, após a Constituição da República de 1988, deve ser acessível aos cidadãos e transparente, vista a atual importância do modelo de governança colaborativa. Considerando que os instrumentos de participação política podem permitir a organização e otimização do processo de tomada de decisões públicas envolvendo cidadãos, optou-se por efetuar uma análise crítica dos aspectos diversos da aplicação da técnica de nudge na área política de políticas públicas. Também se poderou sobre a necessidade de sua adequação às especificidades democráticas e constitucionais de nossa sociedade, visando proteger a liberdade de escolha e de atuação dos agentes sociais que participam comumente das deliberações com o Poder Público. Por meio da metodologia de análise sob a perspectiva sociopolítica e constitucional sobre o contexto brasileiro, concluiu-se que o nudge poderia ser, potencialmente, aplicado no Brasil.

Palavras-chave: Democracia. Direitos fundamentais. Nudge. Paternalismo. Políticas Públicas.

\section{Abstract}

This article purposes to critically reflect on the feasibility of applying the nudge technique in public decision-making processes involving state and citizens from the perspective of soft paternalism as proposed by Thaler and Sunstein. The agenda setting and other stages of public policies, according to the democratic model assumed by the Brazilian State after the Republican Constitution of 1988 must be accessible to citizens and transparent deeming the current significance of the collaborative governance model. Whereas 
that the instruments of political participation can allow the organization and optimization of the public decision-making process involving citizens, one decided to carry out a critical analysis of the multiple aspects of applying the nudge technique in the political area of public policies. The need to adapt them to the democratic and constitutional particular features of our society was also strengthened in order to protect the freedom of choice and action of the social agents who regularly participate in the deliberations with the Public Power. Through the analysis methodology from socio-political and constitutional perspective on the Brazilian context, one concluded that nudge could potentially be applied in Brazil.

Keywords: Democracy. Fundamental rights. Nudge. Paternalism. Public policies.

\section{INTRODUÇÃO}

O presente artigo procura investigar se as conquistas obtidas pelos cidadãos com a Constituição Cidadã de 1988, em relação aos direitos fundamentais, podem ser prejudicadas pelo uso do nudge no processo de tomada de decisões públicas das quais participem os cidadãos. Ou se, por outro lado, podem servir para otimizar a formulação da agenda de políticas sociais. Essa reflexão é crucial nos tempos atuais porque a promulgação da vigente Constituição da República completa trinta anos de sua vigência após a redemocratização do Estado brasileiro posteriormente ao regime de ditadura militar, o qual perdurou por, também, três décadas. A Carta Constitucional de 1988 fez surgir, então, uma nova forma de gestão pública pautada na governança colaborativa, ou governança em rede.

Governar em rede, de acordo com Goldsmith e Eggers, significa sintetizar quatro tendências atuais das relações entre o setor público e o setor privado: inserir os cidadãos nas decisões públicas, coordenar a gestão governamental, garantir o acesso digital e incrementar o fornecimento de bens e serviços públicos ${ }^{1}$. É uma nova metodologia de governança, mais apropriada para o cenário nacional que se formou após a CR/1988. Nesse cenário voltado ao desenvolvimento do amadurecimento democrático,

estratégias governamentais para uma governança eficiente passam por tornar o Estado mais permeável à influência da sociedade, participando diretamente, quando viável. ${ }^{2}$

Essa governança permeável, que é mais propícia ao processo compartilhado de tomada de decisões sobre políticas públicas, demanda uma estrutura governamental por denominada de Estado Resiliente 3 .

O Estado Resiliente foi, de certa forma, fundado pelos brasileiros em 1988 e consiste em uma infraestrutura política que reconhece direitos, dialoga com a sociedade civil, acolhe os argumentos dos cidadãos antes de tomar decisões públicas e garante o equilíbrio da pluralidade social ${ }^{4}$. Seu principal papel político-jurídico é reafirmar os valores constitucionais consignados no documento máximo do país para assegurar que não se retorne ao totalitarismo e opressão em que se viveu em décadas passadas. Por isso, considerando os problemas brasileiros de proteção das liberdades cívicas, a proposta de aplicação da técnica de nudge deve, sim, ser analisada com cautela. Todavia, isso não impede que esta possa contribuir para otimizar processos públicos de decisão envolvendo muitos sujeitos como se pretende com a CR/1988. Os Conselhos estaduais e

1 GOLDSMITH, Stephen; EGGERS, William D. Governar em rede: o novo formato do setor público. Brasília: Escola Nacional de Administração Pública. ENAP: UNESP, 2011. p. 24-35

2 BENTO, Leonardo Valles. Governança e governabilidade na reforma do Estado: entre eficiência e democratização. São Paulo: Manole, 2003.

3 SOUZA, Luciana Cristina de. Aplicação do princípio da resiliência às relações entre Estado, sociedade e direito. In: ASENSI, Felipe Dutra; PAULA, Daniel Giotti de (Org.). Tratado de direito constitucional. Rio de Janeiro: Campus Jurídico, 2014. p. 197-209. (Cap. 2.5). p. 197 .

4 SOUZA, Luciana Cristina de. Refundação do estado democrático de direito pela sociedade civil. In: CONGRESSO BRASILEIRO DE SOCIOLOGIA: GT10: Estado, Cidadania e Identidade, Grupo 4: Estado, Democracia e Sociedade Civil, 13., 2007, Recife (PE), Anais... Recife, 29 de maio a 1 de junho de 2007. Disponível em: <file:///C:/Users/prof/Downloads/sbs2007_gt04_ luciana_de_souza.PDF>. Acesso em: 2 maio 2018. p. 5. 
municipais, por exemplo, possuem um número mais viável de deliberantes; no entanto, conferências, fóruns, audiências públicas e outros meios de participação popular estão abertos a um número maior de atores sociais, logo, precisam de algum tipo de metodologia que melhor os organize para que se possa, efetivamente, extrair uma decisão executável pelo Poder Público.

Exemplo do que este artigo pretende debater é o Orçamento Participativo (OP). Essa metodologia de participação assegura a liberdade de escolha dos cidadãos quanto às obras de seu interesse por meio do processo de formação da lista e de votação nas regionais — o que também aproxima a decisão da realidade de intervenção das políticas públicas. O OP, porém, precisa ser executável do ponto de vista técnico e orçamentário, além de garantir que articulações majoritárias obscureçam os direitos de grupos menos empoderados. Para que isso não aconteça, a aplicação da técnica nudge propicia um guia de participação e de escolha das obras que resulte em um pleito não somente vencedor sob a ótica democrática, como igualmente prático e realizável para não frustrar os vencedores e o restante da população que também se beneficiaria do bem ou serviço demandado. Os laudos técnicos, os critérios de escolha e de votação, a circunscrição às subdivisões dos municípios e das demais normas de orientação sobre como proceder durante as decisões públicas a serem tomadas em um OP são necessárias para fomentar a participação direta efetiva.

Acredita-se que outras modalidades de deliberação abertas a públicos mais numéricos precisam incorporar um conjunto maior de normas que orientem a participação popular com o intuito de preservar a liberdade de atuação dos atores e, ainda, assegurar que uma decisão viável possa ser efetivamente extraída do debate para ser executada pelo Poder Público.

O aspecto da liberdade (libertário, privado) deve, portanto, harmonizar-se com o aspecto social (paternalista, inclusivo) segundo o modo de aplicação da técnica de nudge às políticas públicas proposto por Thaler e Sunstein. A perspectiva do uso da técnica de nudge em políticas públicas como uma forma de soft paternalism apresentada por esses autores se inspirou em pesquisa por eles observada quanto à possibilidade de influenciar as escolhas dos estudantes nas escolas públicas estadunidenses quanto à merenda escolar (bandejões), visando orientar a decisão das crianças e adolescentes de se alimentarem com produtos mais saudáveis ${ }^{5}$.

Thaler e Sunstein estudaram o trabalho dos pesquisadores e agentes relacionados ao setor de alimentação daquelas escolas e escolheram este como o seu leading case para, com base nesse ponto, conduzirem seus próprios estudos sobre aplicação do nudge em políticas públicas considerando não somente o aspecto comportamental, mas também a correlação dessa técnica com os mecanismos usados em processos de tomada de decisão envolvendo Estado e cidadãos. Um dos objetivos, como explica Cass Sunstein, é buscar simplicidade e acesso ao governo para os cidadãos e isto se somaria ao fato de "os nudges oferecerem grandes benefícios à tomada de decisão, sem impor custos elevados" 6 .

É claro que eles admitem que "mais saudável”, "mais benéfico", "dignidade”, "reconhecimento" são categorias, dentre outras, que detêm um certo aspecto subjetivo. Assim, para evitar que uma decisão pública seja manipulada por técnicas de nudging, é muito importante garantir o respeito à base democrática que o novo modelo de governança instaurado com a Constituição da República de 1988, para desse modo respeitar a pluralidade de atores. A proposta de nudge desenvolvida por Thaler e Sunstein considera a essencialidade da garantia das liberdades individuais, mesmo em um sistema mais protecionista, por eles denominado de paternalista no sentido de ordenamento que assegura direitos, e não no sentido pejorativo da herança histórica brasileira. Para a melhor compreender a maneira de se aplicar a técnica de nugde à democracia brasileira, é fulcral entender a perspectiva de análise desses autores.

5 THALER, Richard H.; SUNSTEIN, Cass R. Nudge. New Haven, Conn.: Yale University Press, 2008. p. 1-3.

6 Demostra SUNSTEIN apud MUNIZ, Veyzon Campos. Simpler: the future of government, de Cass Sustein. Revista Brasileira de Politicas Públicas, v. 5, n. 2, p. 315-319, 2015. p. 317-318. 


\section{Nudge: a proposta de Cass R. Sunstein e Richard H. Thaler}

O termo nudge advém da Língua Inglesa e pode ser traduzido como pequeno empurrão ou cotovelada. Para Cass R. Sunstein e Richard h. Thales, o nudge pode ser considerado como um mecanismo de controle comportamental. Os dois autores possuem em conjunto a obra "Nudge: improving decisions about health, wealth, and happiness" que versa sobre o assunto.

Segundo Cass R. Sunstein, o nudge pode ser conceituado como "liberty-preserving approaches that steer people in a particular directions, but that also allow them to go their own way" ". Isso seria o equivalente a dizer que esse mecanismo é uma iniciativa que direcionaria as pessoas para determinados caminhos, porém, ao mesmo tempo em que aponta a direção para o indivíduo, permite que eles possuam liberdade para segui-lo da forma como desejarem. Esse incentivo ou iniciativa não pode se dar de forma impositiva, uma vez que o nudge pauta pela liberdade do sujeito. Este deve estar livre para escolher o caminho da forma como desejar. Se houver imposição, o nudge está descaracterizado ${ }^{8}$. Dessa forma, o uso do poder estatal para orientar as escolhas mantém-se aberto à contribuição dos cidadãos, preservando sua resiliência organizacional, o que é imprescindível no modelo de governança colaborativa ou "em rede".

Logo, resta evidente o motivo de caracterizar o nudge como um mecanismo de economia comportamental, tendo em vista que está voltado para lidar com o comportamento humano. Esta é uma das razões que atrai as instituições públicas e privadas para atingir seus objetivos específicos. Além disso, os custos para a sua implementação podem ser baixos e a taxa de efetividade é considerada alta. Esses elementos fazem do nudge um grande atrativo. ${ }^{9}$ Dentre as formas de nudges $^{10}$, possuímos o GPS, aplicativos que calculam a quantidade de calorias que foram ingeridas pela pessoa no dia anterior, mensagens de texto que informam o vencimento de uma conta ou que informam o agendamento de uma consulta, o cadastro em planos de pensão, dentre outros ${ }^{11}$.

Esse mecanismo comportamental pode ser utilizado por entidades públicas e privadas. Os entes governamentais podem utilizá-lo com diversos fins, como forma de implantar políticas públicas, de efetivar direitos fundamentais e outros. Dentre os exemplos que Cass R. Sunstein ${ }^{12}$ apresentam, estão os alertas gráficos para cigarros, etiquetas para eficiência energética e economia de combustível, painéis de fatos nutricionais em comidas, o prato de comida que seria um guia simples para comer de forma saudável, regras padrões para programas públicos de assistência, sites que produzem grandes pesquisas públicas e lista determinados itens ${ }^{13}$. Ressalta-se que, para sua boa execução, é mister que os gestores públicos estejam capacitados para assumirem uma nova postura dentro do modelo de governança em rede ${ }^{14}$.

7 SUNSTEIN, Cass R. Nudging: a very short guide. 37 J. Consumer Pol'y 583, Harvard Law School; Harvard University; Harvard Kennedy School (hks), p. 1-7, 23 set. 2014. Disponível em: <https://ssrn.com/abstract=2499658>. Acesso em: 27 abr. 2018 . p. 1

8 SUNSTEIN, Cass R. Misconceptions about nudges. Ssrn Electronic Journal, [s.l.], p. 1-13, 2017. (Elsevier BV. http://dx.doi. org/10.2139/ssm.3033101). Disponível em: <https://papers.ssrn.com/sol3/papers.cfm?abstract_id=3033101>. Acesso em: 3 maio 2018. p. 1.

9 SUNSTEIN, Cass R. Misconceptions about nudges. Ssrn Electronic Journal, [s.l.], p. 1-13, 2017. (Elsevier BV. http://dx.doi. org/10.2139/ssrn.3033101). Disponível em: <https://papers.ssrn.com/sol3/papers.cfm?abstract_id=3033101>. Acesso em: 3 maio 2018.

10 In daily life, a GPS is an example of na nudge; so is an "app" that tells people how many calories they ate during the previous day; so is a text message, informing customers that a bill is due or that a doctor's appointment is scheduled for the next day; so is an alarm clock; so is automatic enrollment in a pension plan; so are the default settings on computers and cell phones; so is a system for automatic payment of credit card bills and mortgages.

11 SUNSTEIN, Cass R. Misconceptions about nudges. Ssrn Electronic Journal, [s.l.], p. 1-13, 2017. (Elsevier BV. http://dx.doi.org/10.2139/ ssrn.3033101). Disponível em: < https://papers.ssrn.com/sol3/papers.cfm?abstract_id=3033101>. Acesso em: 3 maio 2018.

12 In government, nudges include graphic warnings for cigarettes; labels for energy efficiency or fuel economy; "nutrition facts" panels on food; the "Food Plate," which provides a simple guide for healthy eating (see choosemyplate.gov); default rules for public assistance programs (as in "direct certification" of the eligibility of poor children for free school meals); a website like data.gov or data.gov.uk, which makes a large number of data sets available to the public; and even the design of government websites, which list certain items first and in large fonts.

13 SUNSTEIN, Cass R. Nudging: a very short guide. 37 J. Consumer Pol'y 583, Harvard Law School; Harvard University; Harvard Kennedy School (hks), p. 1-7, 23 set. 2014. Disponível em: <https://ssrn.com/abstract=2499658>. Acesso em: 27 abr. 2018. p. 1-2 14 GOLDSMITH, Stephen; EGGERS, William D. Governar em rede: o novo formato do setor público. Brasília: Escola Nacional 
Os nudges são produzidos ou elaborados para que possam simplificar a vida das pessoas ou agregar maior segurança. Eles são utilizados na área da saúde, da educação, em avisos públicos e outros que fazem com que seja reduzida a burocracia e os pesos que as pessoas devem suportar. Em razão disso e por ser um guia, algumas pessoas apontam que é uma forma de paternalismo mais brando. Apesar disso, Cass R. Sunstein aponta que o nudge é desenhado para preservar a escolha feita de forma liberal e, além disso, "new nudges typically replace preexisting ones; they do not introduce nudging where it did no exist before" ${ }^{15}$. Essa ideia de paternalismo é uma das críticas enfrentadas pelos adeptos dos nudges.

Para Cass R. Sunstein, há diversos tipos de paternalismo, considerando o termo de modo mais geral ${ }^{16}$ :

a) soft paternalism, considerado mais libertário porque o direito de participação das pessoas e a proteção jurídica de sua liberdade de escolha é mais relevante do que a burocracia de funcionamento do Estado;

b) hard paternalism, no qual o aspecto burocrático ainda possui um forte peso para a organização dos processos deliberativos envolvendo os cidadãos nas tomadas de decisões sobre políticas públicas;

c) means paternalists modalidade cujo foco central são os meios disponíveis e autorizados para se atingir o objetivo;

d) ends paternalists, modalidade cujo foco são as escolhas finais dos indivíduos.

Para o autor, os nudges se encontram na categoria do means paternalism e soft paternalism ${ }^{17}$, pois as decisões sobre políticas públicas tanto precisam respeitar a liberdade de escolhas dos cidadãos quanto oferecer-lhes meios adequados para participarem do processo de escolha. Isto é importante, conforme se acredita, não somente na perspectiva dos indivíduos, mas deve-se levar em conta as organizações da sociedade civil e outros modos desta se articular em grupos de interesse para participar de processos decisórios. É crucial, em um governo democrático, que exista igual acesso de direitos para os indivíduos, ainda que se protejam os segmentos minoritários contra grupos mais fortes política ou economicamente. Por isso o Estado deve garantir os meios para o cidadão assegurar seu papel de sujeito na vida social, como Defensoria Pública, inclusão digital, writs constitucionais, ação civil pública, participação em conselhos, audiências públicas com pleno acesso à informação sobre as decisões etc.

Esse contexto mais democrático quanto à escolha e manutenção da liberdade pelo indivíduo pode ser descrito como uma modalidade de soft paternalism. Também se classifica como means paternalism, já que a atuação cidadã ocorrerá através dos meios disponibilizados para sua participação, os quais permitem a construção de um caminho para se alcançar determinado objetivo. Sunstein ${ }^{18}$ defende que o uso dos nudges pelo governo deve ser realizado de forma transparente e aberta. Além disso, a possibilidade de adoção do nudge deve ser revista e levada para análise pela população. O autor aponta que o crescimento desse mecanismo se eleva, cada vez mais, devido a alguns fatores como o seu baixo custo para se implementá-lo, a entrega de bons resultados e a manutenção da liberdade daquele que o nudge atinge.

de Administração Pública. ENAP: UNESP, 2011. p. 207-208.

15 SUNSTEIN, Cass R. Nudging: a very short guide. 37 J. Consumer Pol'y 583, Harvard Law School; Harvard University; Harvard Kennedy School (hks), p. 1-7, 23 set. 2014. Disponível em: <https://ssrn.com/abstract=2499658>. Acesso em: 27 abr. 2018 . p. 2. 16 Ressalta-se, aqui, que o termo nudge neste artigo tem sido usado na acepção desse marco teórico, visando sua aplicação jurídicopolítica. Sob a perspectiva do behavioral decision-making na Psicologia, outras abordagens são empregadas e a nomenclatura de Thaler e Sunstein não é adotada. Como a presente pesquisa segue metodologia jurídico-constitucional visando sua aplicação em políticas públicas sob o viés do Direito, mantém-se a classificação mencionada neste tópico. Autores mais específicos da linha de estudo comportamental da Psicologia chamam a atenção para a existência de outras modalidades de nudges. Para maiores informações, ler: HANSEN, Pelle Guldborg. The definition of nudge and libertarian paternalism: does the hand fit the glove? European Journal of Risk Regulation, v. 7, n. 1, p. 155-174, 2016. p. 3-6.

17 SUNSTEIN, Cass R. The storrs lectures: behavioral economics and paternalism. Ssrn Electronic Journal, [s.l.], p. 1-60, 29 nov. 2012. (Elsevier BV. http://dx.doi.org/10.2139/ssrn.2182619). Disponível em: <https://papers.ssrn.com/sol3/papers. cfm?abstract_id=2182619>. Acesso em: 3 maio 2018. p. 7.

18 SUNSTEIN, Cass R. Nudging: a very short guide. 37 J. Consumer Pol'y 583, Harvard Law School; Harvard University; Harvard Kennedy School (hks), p. 1-7, 23 set. 2014. Disponível em: <https://ssrn.com/abstract=2499658>. Acesso em: 27 abr. 2018 . p. 2. 
Para Cass R. Sunstein ${ }^{19}$, existem dez tipos de nudges que são os mais usados e serão explicados a seguir. Dentre eles estão as "default rules" que seriam a inclusão automaticamente das pessoas em programas, por exemplo, de saúde ou educação. Por meio dessa inclusão automática, as pessoas melhorariam suas economias e a sua saúde, uma vez que, por exemplo, um programa de aposentadoria faria com que as pessoas obtivessem uma quantia de dinheiro reservada. Além disso, essa inclusão pouparia as pessoas de escolherem se deveriam ou não aderir ao programa e a qual tipo de programa.

A simplificação, também, é vista como um nudge, uma vez que a complexidade pode causar confusão, o que pode provocar descumprimento de preceitos legais, pode aumentar os gastos e impedir a participação em programas importantes. $\mathrm{O}$ uso de normas sociais a serem divulgadas para as pessoas é visto como um nudge potencial, tendo em vista que mostra com que tipo de comportamento as demais pessoas estão engajadas. Isso funciona mais em comunidades pequenas.

Outro nudge é conhecido como "increases in ease and convence", exemplificado como opções com valor baixo ou comidas saudáveis mais visíveis. Isso porque as pessoas tendem a escolher a opção que é mais fácil. "Disclosure" pode ser traduzido como divulgação. Esse é um nudge que pode alcançar, de forma satisfativa, seu objetivo caso seja feito de forma compreensível e acessível. Os exemplos disso são os dados dos custos econômicos do uso de energia ou dos custos totais de um cartão de crédito que são disponibilizados para as pessoas.

Os avisos e gráficos, também, podem ser utilizados como nudges. Quando alguns riscos estão previstos em determinadas atitudes, um aviso público pode ser eficaz para avisar as pessoas. Para isso é necessário chamar a atenção do público com um aviso que seja feito com letras grande e cores brilhantes. Sunstein afirma que há mais probabilidade de as pessoas seguirem esse aviso quando ele contém os passos para que as pessoas consigam cumpri-lo. Um exemplo nesse caso são as advertências realizadas em caixas de cigarros.

As estratégias de pré-comprometimento como nudges são aquelas nas quais as pessoas se comprometem com um determinado tipo de ação. Quando as pessoas colocam objetivos para elas mesmas, se torna mais fácil alcançá-los quando estabelecem determinadas ações que serão realizadas para isso. Assim, se comprometer com ações específicas durante determinado tempo no futuro é uma forma de motivar as ações e diminuir a procrastinação.

Os lembretes funcionam como nudges, por exemplo, quando são enviados lembretes por e-mail ou mensagem de texto para lembrar do pagamento de contas ou de compromissos agendados. Isso porque as pessoas não realizam determinadas condutas em razão da sua inércia, procrastinação ou pelo esquecimento. Com o lembrete, as pessoas são lembradas de agir rapidamente.

Outro nudge importante pode ser nomeado de "eliciting implementation intentions". Isso quer dizer que as pessoas são mais propensas a realizar determinada atividade se alguém provocar a sua intenção de implementação. A pergunta se a pessoa planeja vota ou se planeja vacinar o filho são exemplos de provocações que podem levar à implementação da atitude que se espera.

Por fim, o último nudge é informar as pessoas da natureza e das consequências das próprias escolhas que fizeram no passado, como informar os valores gastos em seguros de saúde ou em contas de energia elétrica. Se isso fosse realizado, o comportamento das pessoas mudaria para melhorar, a começar por economizar dinheiro.

Após a análise dos exemplos mais relevantes de nudges, é necessário investigar a forma como podem ser implantados. De acordo com Sunstein ${ }^{20}$, há duas maneiras de implantar os nudges em uma sociedade. Dentre

19 SUNSTEIN, Cass R. Nudging: a very short guide. 37 J. Consumer Pol'y 583, Harvard Law School; Harvard University; Harvard Kennedy School (hks), p. 1-7, 23 set. 2014. Disponível em: <https://ssrn.com/abstract=2499658>. Acesso em: 27 abr. 2018 . p. 3-4. 20 SUNSTEIN, Cass R. Nudging: a very short guide. 37 J. Consumer Pol'y 583, Harvard Law School; Harvard University; Harvard Kennedy School (hks), p. 1-7, 23 set. 2014. Disponível em: <https://ssrn.com/abstract=2499658>. Acesso em: 27 abr. 2018 . p. 1. 
as formas, uma delas seria confiar nos nudges já existentes, o que seria muito melhor do que confiar em dados ou teorias abstratas. Por isso, as autoridades públicas ou privadas devem utilizar as pesquisas e os dados reais que possuem, sem necessidade de ser realizar novas investigações. Para o autor, "this approach is the simplest because it does not require new offices and significant additional funding, but only attention to the relevant issues and a focus on the right appointments"'21.

Outra forma de implantar o nudge seria criar uma instituição, a qual tanto poderia ter uma forma minimalista, com cinco pessoas reunindo dados importantes, quanto reunir um time para realizar uma grande pesquisa. As vantagens de ambos os modos seria criar um time dedicado e especializado com muitas informações e voltados para um trabalho relevante. Entretanto, segundo Sunstein ${ }^{22}$, um número crescente de países tem concluído que é mais eficaz reunir um grupo específico de pessoas dedicadas para o nudge.

Portanto, é possível concluir que os nudges são técnicas de controle comportamental que podem ser utilizados por instituições púbicas ou privadas com o fito de alcançar determinados objetivos sem colocar em prejuízo a liberdade do indivíduo que é o alvo. Para conservar o livre arbítrio, é necessário conscientizar e informar os indivíduos de que eles sofrem a influência de um nudge e permitir que possam seguir o caminho que desejarem.

\section{PossibILIDAde de APLICAÇÃo da tÉCNICA DE NUDGE À DEMOCRACIA BRASILEIRA}

Sendo o nudge, um mecanismo de controle comportamental que pode ser utilizado tanto por instituições privadas quanto públicas para se atingir determinados objetivos, coloca-se em discussão a sua implantação na sociedade brasileira frente ao conceito de cidadania e de democracia. A necessidade dessa discussão se encontra no papel desempenhado pelo cidadão em relação ao Estado, as conquistas alcançadas com a Constituição Cidadã de 1988 e às consequências de implantação dos nudges que podem conflitar com os direitos implícitos e explícitos na Carta Magna.

Com as alterações e modificações sofridas pela Constituição da República de 1988, principalmente na década de 1990, o cidadão passou a interagir com a Administração Pública ${ }^{23}$. A proteção e a importância dos direitos fundamentais dada pela Carta Magna, pela legislação infraconstitucional e pelo ordenamento jurídico como um todo, resultou na cobrança pelos cidadãos de que estes fossem efetivados e respeitados pelo Estado, devendo cumprir o que estava disposto em lei. O Estado precisou remodelar o seu papel e buscar formas de cumprir o que havia prometido. Como exemplo, adotou as políticas públicas que são formuladas com o fito de dar cumprimento e efetividade aos direitos fundamentais.

O papel do cidadão também se modificou, por exemplo, a legislação infraconstitucional que passou a regulamentar a participação dos cidadãos nos Conselhos que versam sobre idosos, adolescentes, saúde e educação. E na Constituição, com dispositivos como o artigo 1º, parágrafo único da Constituição da República de 1998 que dispõe que "todo o poder emana do povo, que o exerce por meio de representantes eleitos ou diretamente, nos termos desta Constituição". E o artigo 14, caput que prevê que "a soberania popular será exercida pelo sufrágio universal e pelo voto direto e secreto, com valor igual para todos, e, nos termos da lei, mediante" o disposto nos incisos I a 3, qual seja o plebiscito, referendo e a iniciativa popular, mecanismos de participação popular que expressam a opinião dos cidadãos.

21 SUNSTEIN, Cass R. Nudging: a very short guide. 37 J. Consumer Pol'y 583, Harvard Law School; Harvard University; Harvard Kennedy School (hks), p. 1-7, 23 set. 2014. Disponível em: <https://ssrn.com/abstract=2499658>. Acesso em: 27 abr. 2018 . p. 7. 22 SUNSTEIN, Cass R. Nudging: a very short guide. 37 J. Consumer Pol'y 583, Harvard Law School; Harvard University; Harvard Kennedy School (hks), p. 1-7, 23 set. 2014. Disponível em: <https://ssrn.com/abstract=2499658>. Acesso em: 27 abr. 2018 . p. 7. 23 SOUZA, Luciana Cristina de. Contribuição das práticas de e-cidadania para a formulação, implantação e monitoramento das políticas públicas. Revista Direito Público, Porto Alegre, v. 13, n. 74, p. 187-202, mar./abr. 2017. p. 193. 
A modificação do papel do cidadão é resultante da transformação que o Estado sofreu para se adaptar às novas necessidades e demandas da sociedade, em razão da “[...] adoção de valores democráticos que obrigam o Poder Público a admitir a inclusão dos indivíduos enquanto sujeitos ativos e agentes de mudanças de leis e políticas administrativas" ${ }^{24}$. A origem dessas mudanças reside no princípio da resiliência estatal que advém do poder do cidadão de se movimentar para modificar e reformular o Estado e

[...] deste em absorver as mudanças respeitando a contribuição que os primeiros oferecem, equilibrando o ideal democrático com a necessidade de existência de uma estrutura organizada para atender às demandas coletivas. ${ }^{25}$

Diante dessa capacidade que o Estado e o cidadão possuem para se reorganizar e reestruturar conjuntamente e da necessidade da sua atuação conjunta frente às demandas existentes na sociedade, principalmente na implantação de políticas públicas, o nudge pode ser visto como um mecanismo que contribua, embora não de modo exclusivo e central, para a organização de tais deliberações. Isso porque este é passível de permitir que os entes estatais promovam políticas de efetivação e respeito aos direitos fundamentais, por exemplo, a promoção da saúde física e psicológica, a proteção do meio ambiente, o incentivo a educação, dentre outros.

Uma ação estatal desenvolvida nos moldes dos mecanismos de controle comportamental pode ser identificada como controladora, por isso se devem aliá-la ao Princípio da Transparência e da Liberdade para que não prejudique a cidadania e a democracia ${ }^{26}$. Esse controle pode ser prejudicial aos princípios constitucionais e aos direitos fundamentais dos cidadãos, por isso, cabe salientar que tanto na sociedade brasileira quanto em outra sociedade, "quando não se causa prejuízo aos indivíduos, deve o Estado se valer dos 'nudges’ — formas de indução de comportamento, ou, literalmente, de 'dar empurrões’ — para incentivar certas condutas $^{27}$, , ou seja, se o nudge for passível de causar qualquer forma de prejuízo, não deve ser utilizado. Isso porque, sendo o Estado responsável por promover e zelar pelo bem-estar social da sociedade e dos indivíduos, cada um na sua individualidade, não poderia agir de forma negativa perante seus cidadãos.

Especificamente, a Constituição da República de 1998 estabelece, em seu artigo 3º , determinados objetivos que o Estado brasileiro deve perquirir e se identificam com a proposta de melhorias para a sociedade, como o inciso I que procura a construção de uma sociedade livre, justa e solidária ou o inciso IV que dispõe sobre a promoção do bem de todos, sem preconceitos de origem, raça, sexo, cor, idade e quaisquer outras formas de discriminação. Portanto, sendo compatível com os objetivos constitucionais e com os direitos fundamentais, não há objeção à aplicação do nudge.

E, por mencionar a aplicação da Carta Magna, é necessário ressaltar que a aplicação do mecanismo de controle social pelo Estado é visto como uma intervenção estatal, e por isso, deve “[...] seguir os mesmos princípios democráticos e constitucionais que se aplicam às formas tradicionais de regulação ${ }^{28}$ ”. Faz-se imprescindível que o Princípio da Transparência seja respeitado, as pessoas precisam ter ciência de qual nudge será utilizado, onde será aplicado e quais os objetivos que se pretendem, para que dessa forma seja evitado

24 SOUZA, Luciana Cristina de. Contribuição das práticas de e-cidadania para a formulação, implantação e monitoramento das políticas públicas. Revista Direito Público, Porto Alegre, v. 13, n. 74, p. 187-202, mar./abr. 2017. Disponível em: <https://www.academia. edu/33139172/Pra_ticas_de_E-Cidadania_para_Implantac_a_o_de_Poli_ticas_Pu_blicas $>$. Acesso em: 3 maio 2018. p. 193.

25 SOUZA, Luciana Cristina de. Contribuição das práticas de e-cidadania para a formulação, implantação e monitoramento das políticas públicas. Revista Direito Público, Porto Alegre, v. 13, n. 74, p. 187-202, mar./abr. 2017. Disponível em: <https://www.academia.edu/33139172/Pra_ticas_de_E-Cidadania_para_Implantac_a_o_de_Poli_ticas_Pu_blicas >. Acesso em: 3 maio 2018. p. 194 26 HORTA, Ricardo Lins. Arquitetura de escolhas, direito e liberdade: notas sobre o "paternalismo libertário". Pensar: Revista de Ciências Jurídicas, Fortaleza, v. 22, n. 2, p. 651-664, maio/ago. 2017. Disponível em: <http://periodicos.unifor.br/rpen/article/ view/5602/pdf>. Acesso em: 2 maio 2018. p. 661

27 HORTA, Ricardo Lins. Arquitetura de escolhas, direito e liberdade: notas sobre o "paternalismo libertário". Pensar: Revista de Ciências Jurídicas, Fortaleza, v. 22, n. 2, p. 651-664, maio/ago. 2017. Disponível em: <http://periodicos.unifor.br/rpen/article/ view/5602/pdf>. Acesso em: 2 maio 2018. p. 655

28 HORTA, Ricardo Lins. Arquitetura de escolhas, direito e liberdade: notas sobre o "paternalismo libertário". Pensar: Revista de Ciências Jurídicas, Fortaleza, v. 22, n. 2, p. 651-664, maio/ago. 2017. Disponível em: <http://periodicos.unifor.br/rpen/article/ view/5602/pdf>. Acesso em: 2 maio 2018. p. 661 
um Estado ditatorial e opressor. Aliado a esse princípio, deve-se somar um debate aberto com a população, para que seja ouvida a opinião dos indivíduos e seja propiciada uma maior transparência do mecanismo.

A liberdade do cidadão, também, se encontra em jogo, por isso, é necessário que o nudge seja realizado nos moldes propostos por Sunstein, de forma transparente e livre. O indivíduo precisa optar se quer seguir ou não o incentivo que o mecanismo de controle comportamental oferece, ele deve ser livre para seguir o seu caminho da forma como desejar. Diante disso, como nem sempre os indivíduos estão aptos a produzir escolhas racionais e eficientes, surge o que os autores chamam de paternalismo libertário.

Richard Thaler e Cass Sunstein sugerem um modelo de interferência estatal na liberdade individual, como um arquiteto de escolhas, com o objetivo de promover ou evitar determinados comportamentos, auxiliando a escolha dos indivíduos para seguirem o melhor caminho na sua árvore decisória, mas sem adotar nenhum tipo de coerção. O propósito da técnica funda-se sobre o ato de tornar os processos decisórios mais fáceis para os indivíduos, com base no exercício de alguma forma de influência nas suas escolhas e comportamentos. Nesse contexto, as atitudes paternalistas que apenas induzam uma certa escolha não implicam violações de direitos individuais. Libertários paternalistas "pretendem tornar mais fácil para as pessoas seguirem seu próprio caminho, $[\ldots]$ não pretendendo oprimir aquelas que querem exercer sua liberdade ${ }^{29 "}$.

De maneira geral, as decisões tomadas são oriundas de influências de padrões de regras e de contextos em que estão inseridos os indivíduos, e, por isso, seria legítima a influência de um arquiteto de escolhas para auxiliar nos processos decisórios dos indivíduos, de modo a tornar suas vidas melhores. Isto é, as decisões tomadas pelos seres humanos são extremamente influenciáveis aos contextos em que se encontram inseridos, o que chancela a legitimidade da assistência Estatal no processo da melhor escolha.

A política de nudges pode conferir alternativa viável para a implementação de políticas públicas em uma sociedade $^{30}$, todavia estudos comportamentais indicam a possibilidade de os indivíduos realizarem escolhas aparentemente contrárias àquilo que seja capaz de proporcionar o seu próprio bem-estar. Além disso, há a possibilidade de que elas não possam ser adequadamente tomadas caso os indivíduos tenham dificuldade em alcançar conhecimento mais aprofundado sobre as alternativas. Por isso, se fala que o nudge precisa ser um paternalismo libertário, uma vez que deve guiar o indivíduo ao mesmo tempo em que deve deixá-lo livre para fazer as escolhas que desejar. Portanto, se o mecanismo de controle comportamental não for opressor e ditador, não há motivo para vetá-lo.

Nesse ponto, é necessário ressalvar que o paternalismo libertário discutido por Sunstein e Thaler é diferente da acepção que o termo recebe nos estudos de Sérgio Buarque de Holanda, os quais discutem e esboçam as características da sociedade brasileira sobre a distribuição de poder por critérios personalistas. Para Holanda, o paternalismo possui suas raízes no quadro familiar e nas origens coloniais brasileiras, o que extrapola, para a área pública, a vida particular e resulta no mau uso dos recursos públicos e das formas de controle do poder político ${ }^{31}$. Uma das razões desse paternalismo foi a formação dos detentores de posições políticas que estavam inseridos no contexto da família patriarcal, o que como consequência gerou a dificuldades destes em separar o domínio público do privado.

Para o funcionário 'patrimonial', a própria gestão política apresenta-se como assunto de seu interesse particular; as funções, os empregos e os benefícios que deles aufere relacionam-se a direitos pessoas do funcionário e não a interesses objetivos, como sucede no verdadeiro Estado burocrático, em que prevalecem a especialização das funções e o esforço para se assegurarem garantias jurídicas aos cidadãos. ${ }^{32}$

29 THALER, Richard H.; SUNSTEIN, Cass R. Nudge. New Haven, Conn.: Yale University Press, 2008. p. 5.

30 THALER, Richard H.; SUNSTEIN, Cass R. Nudge. New Haven, Conn.: Yale University Press, 2008. Ver também: GALUPPO, Marcelo Campos; ROCHA, Bruno Anunciação. Paternalismo libertário no Estado democrático de direito. Revista de Informação Legislativa, Brasília, v. 53, n. 210, p. 135-148, abr./jun. 2016. Disponível em: <http://www2.senado.leg.br/bdsf/bitstream/handle/ id/522902/001073195.pdf>. Acesso em: 3 maio 2018. p. 140.

31 HOLANDA, Sérgio Buarque de. Raízes do Brasil. São Paulo: Companhia das Letras, 2006. p. 80.

32 HOLANDA, Sérgio Buarque de. Raízes do Brasil. São Paulo: Companhia das Letras, 2006. p. 159. 
Segundo o autor, a experiência brasileira de um corpo administrativo dedicados a interesses objetivos é excepcional. Por isso, ele afirma que

ao contrário, é possível acompanhar ao longo de nossa história, o predomínio constante das vontades particulares que encontram seu ambiente próprio em círculos fechados e pouco acessíveis a uma ordenação impessoal ${ }^{33}$.

Logo, predominou na trajetória brasileira houve durante muitas décadas a atuação de um corpo de agentes do Estado que decidia pelos cidadãos e, não visando o interesse público, mas, sim, de acordo com seus próprios anseios. Isto se contrapõe ao paternalismo libertário da forma como foi descrito na obra de Thaler e Sunstein e pode ser classificado como uma forma de hard paternalismo, agravado por características patrimonialistas. ${ }^{34}$

$\mathrm{Na}$ proposta de soft paternalismo, o indivíduo deve ser livre para decidir qual caminho deve seguir e a noção de um Estado paternal se vincula à ideia de um Poder Público que adote medidas concretas, especialmente quanto às políticas públicas, no sentido de proteger os seus cidadãos, sem, contudo, substituir-lhes a vontade. A atuação conjunta do Estado e dos cidadãos seria passível, no sentido de paternalismo de Thaler e Sunstein, de evitar a manipulação do Estado por elites políticas que representassem grupos particulares, uma vez que os cidadãos estariam cientes dos objetivos da ação proposta e teriam acesso aos mecanismos utilizados para atingi-los. Isso porque tal postura seria uma afronta aos direitos conquistados pelos cidadãos.

Assim, a acepção usual do termo paternalismo no Brasil não é adequada para que se compreenda a perspectiva apresentada neste artigo por estar atrelada ao modo de decidir de vários governos em que os cidadãos não eram sujeitos, mas apenas usuários dos serviços públicos oferecidos. Thaler e Sunstein afirmam que, para evitarmos a manipulação do Estado, é mister que se defina qual será o critério de escolha, observar e vetar nudges que sejam capazes de reduzir o nível de cidadania, impedir que os agentes do Estado realizem a escolha pelo indivíduo.

O nudge é compatível com a democracia brasileira e pode ser aplicado desde que sejam respeitados os princípios constitucionais e democráticos. Dessa forma, é necessário afastar qualquer ação que possa manipular o pensamento e as atitudes do cidadão, ele deve ser livre para optar por qual caminho seguir, ou seja, a sua liberdade deve estar em primeiro lugar. Para isso, é necessário que o caminho a ser percorrido até se implantar o nudge seja guiado pelo Princípio da Transparência, informando a sociedade dos objetivos esperados, requerendo a opinião dos cidadãos e demonstrando os resultados alcançados "permitindo ao cidadão o acesso às informações não apenas individuais, mas de interesse coletivo e difuso". ${ }^{35}$

\section{EFEITO “NUDGING" em POLÍtICAS PÚBLICAS}

O Diário Oficial do Município publicou, em 10 de outubro de 2016, a Lei no 10.982 que pró́be a exposição de sal em mesas e balcões de bares, restaurantes, lanchonetes e similares em Belo Horizonte. Caso deseje consumir o sal, o cliente deverá solicitar ao estabelecimento, que disponibilizará, sem exposição, embalagens individuais (sachês) contendo o produto. Atenta aos males proporcionados pelo seu consumo excessivo e os riscos provocados pela hipertensão, temos uma simples demonstração de uma política pública local de saúde que decidiu por "restringir" o consumo de determinado produto, sem, contudo, proibi-lo absolutamente.

33 HOLANDA, Sérgio Buarque de. Raízes do Brasil. São Paulo: Companhia das Letras, 2006. p. 159-160.

34 MOURA, Emerson Affonso da Costa. Transparência administrativa, Lei Federal no 12.527/2011 e sigilo dos documentos públicos: a inconstitucionalidade das restrições ao acesso à informação. Revista Brasileira de Politicas Públicas, v. 6, n. 2, p. 45-64, 2016. p.41.

35 MOURA, Emerson Affonso da Costa. Transparência administrativa, Lei Federal no 12.527/2011 e sigilo dos documentos públicos: a inconstitucionalidade das restrições ao acesso à informação. Revista Brasileira de Políticas Públicas, v. 6, n. 2, p. 45-64, 2016. p. 39 . 
Diante de tal situação, o sujeito A pode escolher consumir o produto em razão de preferência de paladar. O sujeito B, atento aos males do consumo excessivo, pode escolher se abster do consumo. O sujeito C, ciente dos males, pode, ainda, decidir pelo consumo. Diversas são as possibilidades. Os indivíduos podem não conhecer os efeitos do consumo do sal em longo prazo, podem ignorá-los ou podem subestimá-los. Fato é que as escolhas dos indivíduos, muitas vezes, podem direcioná-los a resultados não desejáveis.

Geralmente, com baixo custo e com boa capacidade para favorecer objetivos econômicos e sociais, como no exemplo citado, além de prezar pela liberdade do indivíduo, a utilização de nudges em políticas públicas no Brasil tem encontrado grande potencial. Objetiva-se com tal política, baseada na existência de falhas cognitivas que podem prejudicar os objetivos de bem-estar definidos individualmente, aumentar a probabilidade do indivíduo de seguir o melhor caminho, sem, contudo, obrigá-lo ou enganá-lo.

Para melhor compreender tal fenômeno, a conceituação do que seja política pública se faz imprescindível, apesar de não ser simples, na visão de Howlett e Ramesh. Os autores argumentam que, apesar da concorrência de definições, todas elas postulam que as políticas públicas são ações intencionais de governos que possuem objetivos articulados e meios para alcançá-los, ainda que precariamente identificados, independentemente de como estejam os objetivos interligados aos meios ${ }^{36}$. Para tanto, considerando que a política pública é resultante de um processo complexo consistente na tomada de inúmeras decisões, Howlett e Ramesh condensaram tal processo em cinco etapas: (1) montagem da agenda; (2) formulação da política; (3) tomada de decisão; (4) implementação e (5) avaliação.

O primeiro momento do ciclo, a formação da agenda, é talvez considerada pelos autores o estágio mais crítico dentre todos os cinco, pois o que é decidido nele tem impacto em todo o processo político. A agenda pode ser entendida como o conjunto de problemas elencados suscetíveis de apreciação pelo governo.

O segundo momento recai sobre a formulação da política, ou seja, trata-se do processo de criação de alternativas para solucionar o problema. Há nesse estágio, um refinamento e uma avaliação sobre a viabilidade das opções.

$\mathrm{Na}$ terceira fase do ciclo, tem se a tomada de decisão acerca das opções selecionadas anteriormente. O governo, com base na tomada de decisão, toma um curso de ação a respeito do processo de resolução de um problema.

A quarta etapa é a da implementação da política pública. Nesse estágio há o planejamento e estruturação da máquina pública de forma a viabilizar a execução da política pública.

No quinto e último estágio, tem-se a avaliação do funcionamento e dos efeitos da política pública. Surge nesse momento a possibilidade de manter o que foi estruturado ou de se repensar a política pública, podendo haver o retorno a alguma fase do ciclo para correção de algum ponto.

Nesse modelo de ciclo, prepondera a ideia de que o processo de implementação de uma política pública inicia-se com base na identificação e no reconhecimento de problemas que requeiram atenção por parte do governo, com consequente processo de formulação e refinamento de propostas sobre o que fazer a respeito, e, finalmente, a tomada de uma decisão.

Cada vez mais o Estado é exigido e questionado sobre o desempenho das suas funções, o processo de criação de uma política pública deve levar em consideração, em especial no Brasil, onde há tantas carências, a identificação daquelas que mais necessitam de atenção. Em razão da razoável "facilidade" de implementação, nos últimos anos, a utilização dos Nudges, traduzidos em atos provenientes de instituições privadas ou públicas direcionados ao aprimoramento das decisões dos indivíduos, vem sendo cada vez mais perquirida, de forma a cumprir com o compromisso ideológico e doutrinário dos direitos fundamentais, pilares básicos

36 HOWLETT, M., RAMESH, M., PERL. A. Politicas públicas: seus ciclos e subsistemas: uma abordagem integradora. Rio de Janeiro: Elsevier, 2013. p. 6. 
do Estado Democrático de Direito.

Tal questão torna-se ainda mais relevante no contexto dos 30 anos da promulgação da Constituição de 1988, a chamada "Constituição Cidadã", cuja matriz, o Estado Democrático de Direito, endossa os direitos e garantias fundamentais do indivíduo. Advinda de um período ditatorial, existia um anseio pelo resgate da democracia e da retomada dos direitos fundamentais. Diante disso, indaga-se: se os indivíduos possuem falhas cognitivas, se são facilmente influenciáveis pelo contexto em que se encontram inseridos, porque não exercer a influência no sentido de tornar sua vida melhor?

A criação de políticas públicas pode ser pensada de forma a contribuir aos resultados das escolhas realizadas pelos indivíduos por meio de estímulos e modificações contextuais que dificultam o processo cognitivo de tomada de decisão de acordo com os verdadeiros interesses de cada pessoa. A política de Nudges formulada por Richard Thaler e Cass Sunstein se traduz em "empurrões" direcionados à otimização do processo cognitivo de escolha, com o intuito de usurpar falhas cognitivas que poderiam levar ao indivíduo deixar de fazer escolhas ótimas.

Indaga-se se a utilização dos nudges poderia configurar espécie de indução de comportamento por parte do governo de forma a criar padrões desejados de conduta. O fato de se desejar tornar os processos decisórios mais fáceis para os indivíduos, por meio do exercício de alguma forma de influência nas suas escolhas e comportamentos, poderia configurar instrumento de subversão da sua intrínseca vontade no intuito de conferir êxito na manipulação de comportamento. Dessa forma, o governo poderia direcionar e operar a atuação dos indivíduos de acordo com seus interesses por meio da utilização de políticas previamente estudadas e planejadas para determinado proveito.

Tomemos por exemplo, as audiências públicas utilizadas na formulação de políticas sociais. A Audiência Pública é um instrumento reconhecido e garantido pela Constituição Federal de 1988 e regulado nos níveis municipal, estadual ou federais, que possibilita a participação democrática popular ${ }^{37}$, podendo ocorrer durante os processos de elaboração e aprovação de leis, projetos e políticas públicas, ou para prestação de contas pelo poder Executivo, Legislativo ou do Ministério Público.

E, nesse sentido, o instituto da audiência pública, além de já positivado em inúmeras leis, vem ganhando projeção no cenário jurídico e político nacional como mecanismo de participação no processo decisório, precipuamente nas decisões da Administração Pública, embora também seja previsto no curso do processo legislativo $\left(\mathrm{CR} / 1988\right.$, art. $58, \mathbb{\S} 2^{\circ}$, II).

De fato, é no campo das decisões administrativas que a audiência pública tem mais importância. $O$ Poder Executivo, destinado a atuar a lei de ofício atendendo a interesses públicos, está diante de uma enorme quantidade de casos concretos em que deve agir visando à satisfação das necessidades coletivas. Por seus agentes públicos, toma decisões relevantes cotidianamente, sendo de fundamental importância o debate público sobre muitos desses temas e desafios, permitindo transparência ao processo decisório e conferindo legitimidade à ação administrativa. ${ }^{38}$

Esse instrumento utilizado pela Administração Pública se trata de uma reunião aberta, na qual a autoridade capta as opiniões e demandas da comunidade acerca de determinado tema ${ }^{39}$. Dessa forma, Eduardo Fortunato Bim esclarece que

[...] a audiência pública visa informar e expor o conteúdo da decisão ou futura decisão à sociedade,

37 SOUZA, Luciana Cristina de. Aplicação do princípio da resiliência às relações entre Estado, sociedade e direito. In: ASENSI, Felipe Dutra; PAULA, Daniel Giotti de (Org.). Tratado de direito constitucional. Rio de Janeiro: Campus Jurídico, 2014. p. 197-209. (Cap. 2.5). 38 CABRAL, Antonio. Os efeitos processuais da audiência pública. Boletim Científico: Escola Superior Do Ministério Público da Uniao, Brasilia, v. 24/25, n. 6, p. 41-65, jul./dez. 2007. Disponível em: <http://boletimcientifico.escola.mpu.mp.br/boletins/boletim-cientifico-n.-24-e-n.-25-julho-dezembro-de-2007-1/os-efeitos-processuais-da-audiencia-publica>. Acesso em: 22 maio 2018. p. 42-43.

39 CABRAL, Antonio. Os efeitos processuais da audiência pública. Boletim CientÍfico: Escola Superior Do Ministério Público da Uniao, Brasilia, v. 24/25, n. 6, p. 41-65, jul./dez. 2007. Disponível em: <http://boletimcientifico.escola.mpu.mp.br/boletins/boletimcientifico-n.-24-e-n.-25-julho-dezembro-de-2007-1/os-efeitos-processuais-da-audiencia-publica>. Acesso em: 22 maio 2018. p. 44-45. 
promovendo a discussão sobre o tema ao dirimir as dúvidas e recolher dos presentes as críticas e sugestões a respeito ${ }^{40}$.

Em razão disso, esse mecanismo administrativo pode (deve) ser utilizado para a elaboração das políticas públicas que dialoguem com os mecanismos de nudge. De grande valia para a definição e implantação de políticas públicas, as audiências públicas têm como um dos seus principais objetivos, o incentivo à busca de soluções de problemas públicos por meio da participação de particulares nos temas de interesse comum.

Para tanto, geralmente realizadas por meio de reuniões que visam à discussão das questões envolvidas com a coleta de dados e informações que possam auxiliar a elaboração e satisfação de interesses, as audiências públicas, são abertas para todo o público, não podendo haver restrição de participação a grupos determinados, sendo, fundamental que o órgão que a convoca priorize a presença das pessoas diretamente afetadas pela política pública ou projeto de lei a ser discutido. Além de constituírem instrumento essencial para a implementação de políticas públicas, elas podem ser feitas, também, após sua implantação para discussão e avaliação de seus resultados e impactos na sociedade.

A audiência pública constitui um espaço de democracia participativa inserida no contexto do Estado Democrático de Direito, endossante dos direitos e garantias fundamentais do indivíduo. Nesse sentido, o cidadão não pode ser, apenas, um mero espectador dos feitos do poder público. Além de ser detentor de direito e garantias, os indivíduos possuem, também, deveres perante a sociedade, na medida em que a vida em sociedade demanda uma postura colaborativa em busca de um bem comum. Dessa forma, os cidadãos teriam um dever cívico de participar das decisões do poder público em tudo aquilo que concerne aos interesses comuns de forma a produzir as melhores escolhas possíveis.

Nesse sentido, Maria Goretti Dal Bosco ${ }^{41}$ pontua que o cidadão

além de ser alguém que exerce direitos, cumpre deveres ou goza de liberdades em relação ao Estado, ele é também o titular, mesmo que de forma parcial, de uma função ou de um poder público.

Assim, nos dizeres do $\$ 1^{\circ}$, do art. $1^{\circ}$ da Constituição Federal de 1988 , todo o poder emana do povo que o deve exercer de forma direta ou com base nos seus representantes legais.

A audiência pública "[...] é um mecanismo eficiente na busca do aperfeiçoamento dos mecanismos de definição das prioridades de investimentos estatais nas chamadas políticas públicas [... ${ }^{42}$ ", uma vez que, por meio delas, é possível ouvir os cidadãos, compreender a opinião e permitir a participação deles. Em razão disto, as audiências públicas estão intrinsicamente ligadas aos mecanismos de nudges, uma vez que, por meio desse instrumento administrativo, é possível definir o nudge que será aplicado à política pública. Ademais, a audiência pública é uma forma de mostrar para a sociedade que determinado nudge será utilizado, respeitando o Princípio da Publicidade, e evitando a manipulação do governo.

Como dito, além da preocupação ética e democrática, também é importante que existam critérios claros e compreensíveis por todos os atores sociais que participarão dos instrumentos deliberativos, como o OP, os conselhos, as conferências, as audiências públicas etc. No caso dessas últimas, um exemplo são as normas do Manual da Agência Nacional de Energia Elétrica - ANEEL ${ }^{43}$. Esse normativo especifica que "Audiência

40 BIM, Eduardo Fortunato. Audiências públicas no direito administrativo e ambiental. In: DE MORAES, Alexandre; KIM, Richard Pae (Coord.). Cidadania: o novo conceito jurídico e a sua relação com os direitos fundamentais, individuais e coletivos. São Paulo: Atlas, 2013. p. 216.

41 BOSCO, Maria Goretti Dal. Audiência pública como direito de participação. Revista Jurídica Unigran, Dourados, v. 4, n. 8, p. 137-157, jul./dez. 2002. Disponível em: <http://www.unigran.br/revista_juridica/ed_anteriores/08/artigos/10.pdf>. Acesso em: 22 maio 2018. p. 137.

42 BOSCO, Maria Goretti Dal. Audiência pública como direito de participação. Revista Jurídica Unigran, Dourados, v. 4, n. 8, p. 137-157, jul./dez. 2002. Disponível em: <http://www.unigran.br/revista_juridica/ed_anteriores/08/artigos/10.pdf>. Acesso em: 22 maio 2018. p. 156.

43 AGÊNCIA NACIONAL DE ENERGIA ELÉTRICA - ANEEL. Manual de normas de procedimentos: audiências públicas. Brasília, 2005. v.3. Disponível em: <http://www2.aneel.gov.br/aplicacoes/audiencia/arquivo/2005/033/documento/procedimentosap. 
Pública é um instrumento de apoio ao processo decisório da ANEEL, de ampla consulta à sociedade, que precede a expedição dos atos administrativos" 44 e serve para recolher informações para o processo decisório da ANEEL, possibilitar o encaminhamento de solicitações de consumidores e clientes, dar publicidade à ação regulatória da ANEEL, entre outros objetivos de transparência. Em 2018 já foram realizadas diversas audiências públicas, destacando-se:

a) ANEEL - AP n. 22/2018: obter subsídios para a definição dos indicadores e das metas da Performance Organizacional - PO do Operador Nacional do Sistema Elétrico - ONS para o ciclo de janeiro a dezembro de 2019 (Modalidade: intercâmbio documental; Período: 18/05 a 17/06 de 2018);

b) ANEEL - AP n. Obter subsídios para regulamentar a aplicação de penalidades por falha no suprimento de combustível, conforme o disposto na Resolução no 18/2017, emitida pelo Conselho Nacional de Política Energética - CNPE (Modalidade: intercâmbio documental; Período: 18/05 a 17/06 de 2018).

In casu, foi escolhida uma modalidade específica, mais rápida e fácil de se organizar, mas há outras previstas em seu Manual de Procedimentos. A ANEEL atua com as seguintes modalidades de AP:

i) Audiência Pública ao vivo - Presencial, de "viva voz";

ii) Audiência Pública Descentralizada - Presencial nas regionais e conveniadas;

iii) Audiência Pública Simultânea - Presencial e teleconferência com as regionais e conveniadas;

iv) Audiência para o Público Interno - Unidades Organizacionais da ANEEL;

v) Audiência Pública por Intercâmbio Documental - Envio de sugestões por escrito, aberto a toda a sociedade civil.

Para consolidar os debates feitos, a ANEEL adota a metodologia de redigir uma Ata das Audiências, bem como um Relatório contendo os elementos a seguir: área responsável, os fatos ocorridos até a data da instauração da AP, descrição de sua evolução, votação, arcabouço legal e a decisão da Diretoria. Além disso, toda a documentação necessária para leitura prévia deve ser disponibilizada. Todas as manifestações devem ser reduzidas a termo ou gravadas para consulta posterior pelos deliberantes, mas compete à Diretoria da área responsável definir os critérios de participação, os tópicos mais relevantes para o momento e definir o tipo de organização das informações disponibilizadas. Como visto, "mais relevante" é tecnicamente decidido, mas possui, ainda, um aspecto subjetivo. Por isso é crucial preservarem-se os valores constitucionais democráticos de 1988 para que essa metodologia de otimização de decisões públicas seja, efetivamente, um contributo para o aperfeiçoamento dos instrumentos deliberativos.

\section{Considerações finais}

Logo, considerando a proposta inicial de analisar se as conquistas obtidas pelos cidadãos com a Constituição Cidadã de 1988 sofreriam prejuízos pelo uso da técnica de nudge no processo de tomada de decisões públicas, como no exemplo citado das audiências públicas, conclui-se que tal solução pode permitir que algumas deliberações fluam melhor e que se possa extrair um resultado — no caso o Relatório — mais aplicável, otimizando o resultado, como na organização da disposição dos alimentos no bandejão escolar nos EUA na pesquisa inicial de Thaler e Sunstein. Da mesma forma, podem propiciar em outras situações, como o OP e outros meios deliberativos diretos da democracia contemporânea, o desenvolvimento da governança colaborativa, ou flexível, no âmbito do Estado Resiliente.

pdf>. Acesso em: 28 maio 2018.

44 AGÊNCIA NACIONAL DE ENERGIA ELÉTRICA - ANEEL. Procedimento para audiência e consulta pública. Disponível em: <http://www2.aneel.gov.br/aplicacoes/consulta_publica/documentos/Procedimentos\%20AP-CP.pdf>. Acesso em: 28 maio 2018. 
Mas gráficos, tabelas e outros meios de informação precisam ser transparentes e representar a pluralidade social brasileira, para evitar sua manipulação no momento da tomada de decisão por parte dos atores sociais ou equívocos quanto ao modo de implementar a técnica de nudge. Orientar comportamentos pode permitir melhor aplicação do orçamento público, por exemplo, em razão da aproximação entre a decisão dos cidadãos e os laudos técnicos. Pode permitir que opiniões distintas de grupos envolvidos e conhecedores da realidade de intervenção sejam ouvidos e tenham, igualmente, influência sobre as ações dos gestores públicos.

Dessa forma, a proposta de Thaler e Sunstein de aplicação da técnica nudge é viável na democracia brasileira para a modalidade de soft paternalismo e means paternalism, desde que sejam respeitados os valores constitucionais de publicidade, diversidade e igualdade entre os cidadãos para que nenhuma grupo sub-empoderado fique à mercê de outro mais forte política, jurídica, econômica ou digitalmente. O cenário mais viável é aquele em que as informações estejam plenamente acessíveis e sejam confiáveis; também aquele no qual não haja superposição constante da maioria contra interesses minoritários, o que reduziria a democracia pátria a um critério meramente numérico e não qualitativo. A redação de regras claras de participação pelos órgãos públicos aponta para uma solução porque esses manuais tanto esclarecem aos atores sobre o modo de sua participação como, ainda, servem de documento que, por estarem disponíveis, podem ser criticamente avaliados de modo contínuo pelos cidadãos, o que garantirá o funcionamento do nudge no âmbito democrático que dele se espera para fortalecer os preceitos fundamentais da trintenária Constituição da República de 1988, a Carta Cidadã.

\section{REFERÊNCIAS}

AGÊNCIA NACIONAL DE ENERGIA ELÉTRICA - ANEEL. Manual de normas de procedimentos: audiências públicas. Brasília, 2005. v.3. Disponível em: <http://www2.aneel.gov.br/aplicacoes/audiencia/arquivo/2005/033/documento/procedimentosap.pdf>. Acesso em: 28 maio 2018.

AGÊNCIA NACIONAL DE ENERGIA ELÉTRICA - ANEEL. Procedimento para audiência e consulta pública. Disponível em: <http://www2.aneel.gov.br/aplicacoes/consulta_publica/documentos/Procedimentos\%20AP-CP.pdf>. Acesso em: 28 maio 2018.

BENTO, Leonardo Valles. Governança e governabilidade na reforma do Estado: entre eficiência e democratização. São Paulo: Manole, 2003.

BIM, Eduardo Fortunato. Audiências públicas no direito administrativo e ambiental. In: DE MORAES, Alexandre; KIM, Richard Pae (Coord.). Cidadania: o novo conceito jurídico e a sua relação com os direitos fundamentais, individuais e coletivos. São Paulo: Atlas, 2013.

BITTAR, Eduardo C. B. Metodologia da pesquisa jurídica. 14. ed. São Paulo: Saraiva, 2016.

BOSCO, Maria Goretti Dal. Audiência pública como direito de participação. Revista Jurídica Unigran, Dourados, v. 4, n. 8, p. 137-157, jul./dez. 2002. Disponível em: <http://www.unigran.br/revista_juridica/ ed_anteriores/08/artigos/10.pdf>. Acesso em: 22 maio 2018.

BRASIL. Constituição (1988). Constituição da República Federativa do Brasil, promulgada em 5 de outubro de 1988. Disponível em: < http://www.planalto.gov.br/ccivil_03/constituicao/constituicao.htm>. Acesso em: 22 jul. 2015.

CABRAL, Antonio. Os efeitos processuais da audiência pública. Boletim Científico: Escola Superior Do Ministério Público da Uniao, Brasilia, v. 24/25, n. 6, p. 41-65, jul./dez. 2007. Disponível em: <http:// boletimcientifico.escola.mpu.mp.br/boletins/boletim-cientifico-n.-24-e-n.-25-julho-dezembro-de-2007-1/ os-efeitos-processuais-da-audiencia-publica>. Acesso em: 22 maio 2018. 
EPSTEIN, Lee; KING, Gary. Pesquisa empírica em direito: as regras de inferência. São Paulo: Direito GV, 2013.

GALUPPO, Marcelo Campos; ROCHA, Bruno Anunciação. Paternalismo libertário no Estado democrático de direito. Revista de Informação Legislativa, Brasília, v. 53, n. 210, p. 135-148, abr./jun. 2016. Disponível em: <http://www2.senado.leg.br/bdsf/bitstream/handle/id/522902/001073195.pdf>. Acesso em: 3 maio 2018.

GOLDSMITH, Stephen; EGGERS, William D. Governar em rede: o novo formato do setor público. Brasília: Escola Nacional de Administração Pública. ENAP: UNESP, 2011.

HANSEN, Pelle Guldborg. The definition of nudge and libertarian paternalism: does the hand fit the glove? European Journal of Risk Regulation, v. 7, n. 1, p. 155-174, 2016.

HOLANDA, Sérgio Buarque de. Raízes do Brasil. São Paulo: Companhia das Letras, 2006.

HORTA, Ricardo Lins. Arquitetura de escolhas, direito e liberdade: notas sobre o "paternalismo libertário”. Pensar: Revista de Ciências Jurídicas, Fortaleza, v. 22, n. 2, p. 651-664, maio/ago. 2017. Disponível em: $<$ http://periodicos.unifor.br/rpen/article/view/5602/pdf>. Acesso em: 2 maio 2018.

HOWLET'T, M., RAMESH, M., PERL. A. Políticas públicas: seus ciclos e subsistemas: uma abordagem integradora. Rio de Janeiro: Elsevier, 2013.

MOURA, Emerson Affonso da Costa. Transparência administrativa, Lei Federal nº 12.527/2011 e sigilo dos documentos públicos: a inconstitucionalidade das restrições ao acesso à informação. Revista Brasileira de Políticas Públicas, v. 6, n. 2, p. 45-64, 2016.

MUNIZ, Veyzon Campos. Simpler: the future of government, de Cass Sustein. Revista Brasileira de Politicas Públicas, v. 5, n. 2, p. 315-319, 2015.

SOUZA, Luciana Cristina de. Aplicação do princípio da resiliência às relações entre Estado, sociedade e direito. In: ASENSI, Felipe Dutra; PAULA, Daniel Giotti de (Org.). Tratado de direito constitucional. Rio de Janeiro: Campus Jurídico, 2014. p. 197-209. (Cap. 2.5)

SOUZA, Luciana Cristina de. Contribuição das práticas de e-cidadania para a formulação, implantação e monitoramento das políticas públicas. Revista Direito Público, Porto Alegre, v. 13, n. 74, p. 187-202, mar./abr. 2017. Disponível em: <https://www.academia.edu/33139172/Pra_ticas_de_E-Cidadania_para_ Implantac_a_o_de_Poli_ticas_Pu_blicas>. Acesso em: 3 maio 2018.

SOUZA, Luciana Cristina de. Refundação do estado democrático de direito pela sociedade civil. In: CONGRESSO BRASILEIRO DE SOCIOLOGIA: GT10: Estado, Cidadania e Identidade, Grupo 4: Estado, Democracia e Sociedade Civil, 13., 2007, Recife (PE), Anais... Recife, 29 de maio a 1 de junho de 2007. Disponível em: <file:///C:/Users/prof/Downloads/sbs2007_gt04_luciana_de_souza.PDF>. Acesso em: 2 maio 2018.

SUNSTEIN, Cass R. Misconceptions about nudges. Ssrn Electronic Journal, [s.l.], p. 1-13, 2017. (Elsevier BV. http://dx.doi.org/10.2139/ssrn.3033101). Disponível em: <https://papers.ssrn.com/sol3/papers. cfm?abstract_id=3033101>. Acesso em: 3 maio 2018.

SUNSTEIN, Cass R. Nudging: a very short guide. 37 J. Consumer Pol'y 583, Harvard Law School; Harvard University; Harvard Kennedy School (hks), p. 1-7, 23 set. 2014. Disponível em: < https://ssrn.com/ abstract $=2499658>$. Acesso em: 27 abr. 2018.

SUNSTEIN, Cass R. The storrs lectures: behavioral economics and paternalism. Ssrn Electronic Journal, [s.1.], p. 1-60, 29 nov. 2012. (Elsevier BV. http://dx.doi.org/10.2139/ssrn.2182619). Disponível em: < https://papers.ssrn.com/sol3/papers.cfm?abstract_id=2182619>. Acesso em: 3 maio 2018.

THALER, Richard H.; SUNSTEIN, Cass R. Nudge. New Haven, Conn.: Yale University Press, 2008. 
Para publicar na revista Brasileira de Políticas Públicas, acesse o endereço eletrônico www.rbpp.uniceub.br

Observe as normas de publicação, para facilitar e agilizar o trabalho de edição. 